\title{
Analysis of the Urban Thermal Fingerprint of the City of Trento in the Alps
}

\author{
LORENZO GIOVANNINI AND DINO ZARDI \\ Atmospheric Physics Group, Department of Civil and Environmental Engineering, University of Trento, Trento, Italy \\ MASSIMILIANO DE FRANCESCHI \\ Atmospheric Physics Group, Department of Civil and Environmental Engineering, University of Trento, Trento, Italy, and \\ Major Seminary, Diocese of Bolzano-Bressanone, Bressanone, Italy
}

(Manuscript received 4 August 2010, in final form 19 November 2010)

\begin{abstract}
The temperature contrasts typically marking urban heat island (UHI) effects in the city of Trento, Italy, located in an Alpine valley and inhabited in its inner urban area by a population of about 56000 , are investigated. Time series of air temperature data, collected at an urban weather station, in the city center, and at five extraurban stations are compared. The latter are representative of rural and suburban areas, both on the valley floor and on the valley sidewalls. It is found that the extraurban weather stations, being affected by different local-scale climatic conditions, display different temperature contrasts with the urban site. However, the diurnal cycle of the UHI is characterized by similar patterns of behavior at all of the extraurban weather stations: the UHI intensity is stronger at night, whereas during the central hours of the day an "urban cool island" is likely to occur. The diurnal maximum UHI intensity turns out to be typically of order $3^{\circ} \mathrm{C}$, but under particularly favorable conditions it may be higher than $6^{\circ} \mathrm{C}$. An urban cool island effect is also detected, which is probably caused by the compactness of the inner urban area, and displays typical diurnal maximum intensities of order $1.5^{\circ} \mathrm{C}$. As to the seasonal dependence, at the extraurban weather stations on the valley floor the UHI intensity tends to be slightly stronger during dry months, whereas on the valley sidewalls it is mainly influenced by the seasonal lapse-rate changes. Further weather factors, such as wind speed and cloud cover, also affect urbanization effects, making them weaker with stronger winds and cloudier skies.
\end{abstract}

\section{Introduction}

Urban areas are known to display different climatic conditions than the surrounding countryside, primarily associated with the so-called urban heat island (UHI), that is, with higher values of surface air temperature occurring in the city center than in surrounding rural areas.

The UHI effect is mainly due to the strong modifications produced in the surface energy budget by urban surfaces covered with artificial materials (buildings, paved roads, etc.). However, another important factor is the strongly three-dimensional character of the elements composing a city structure (i.e., buildings, streets, etc.), which reduces both the ventilation in the gaps between buildings and the sky-view factor from the interior of the streets (Oke

Corresponding author address: Lorenzo Giovannini, Atmospheric Physics Group, Dept. of Civil and Environmental Engineering, University of Trento, Via Mesiano, 77, I-38123 Trento, Italy.

E-mail: lorenzo.giovannini@ing.unitn.it
1987). Both of these effects contribute to the "trapping" of heat within urban canyons. Further sources of "anthropogenic" heat are indoor heating and cooling facilities, traffic, as well as other activities.

The UHI intensity is usually evaluated by means of typical differences $\left(\Delta T_{u-r}=T_{u}-T_{r}\right)$ between values of the surface air temperature inside the urban environment $T_{u}$ and in the countryside outside of the city $T_{r}$. UHI intensity varies during the day (being generally higher during nighttime than during daytime) and depends on weather factors (in particular, wind speed and cloud cover), which basically modify the turbulent and radiative cooling at night (Morris et al. 2001; Kassomenos and Katsoulis 2006). Hence, maximum UHI intensities are generally reached during clear nights, especially at low wind speeds.

To date, most of the research on urban meteorology has concentrated on relatively big cities, which are mostly located over flat areas, whose climate is relatively simple to characterize, as it mainly depends on synoptic-scale 
factors and on boundary layer processes over flat terrain (Landsberg 1981; Oke 1987). The picture becomes more complicated for cities lying in areas displaying geographic inhomogeneities, such as coastal regions, as well as areas displaying strongly heterogeneous land use or complex terrain. Here, the investigation of the UHI must take into account the interactions between the built-up area and the complex meteorological phenomena typical of these areas. In fact in complex terrain mesoscale and local-scale phenomena may be even more important than synopticscale factors in affecting the meteorology at all scales down to the boundary layer processes, which display features strongly marked by the local topography and ground properties (Rotach and Zardi 2007; de Franceschi et al. 2009; de Franceschi and Zardi 2009). For this reason, Stewart (2010) pointed out that UHI studies must carefully avoid the use of data from instrumental settings that cannot distinguish urban effects from other extraneous effects produced by surface relief and elevation.

Several works have analyzed the climate of coastal cities and the interactions with sea-breeze circulations (e.g., Gedzelman et al. 2003; Cenedese and Monti 2003; Thompson et al. 2007). On the other hand, the urbanclimate properties of cities located in mountain valleys have received less attention, although various cases of midsized cities in mountain areas can be found all over the world, whereas only a handful of works on them are available in the literature.

Mountain valleys are often characterized by daily periodic, thermally driven circulation systems, such as slope winds, blowing along sidewall slopes, and along-valley winds (Whiteman 1990; D. Zardi and C. D. Whiteman 2010, unpublished manuscript). Slope winds are generated from the heating-cooling of the air close to the valley slopes, and are generally upslope during daytime and downslope during nighttime (Serafin and Zardi 2010a,b). The along-valley winds, which typically blow up-valley during the day and down-valley at night, are generated by the horizontal pressure gradients due to the temperature differences between different cross sections of the valley or between the valley and the adjacent plain (Rampanelli et al. 2004). In fact, diurnal temperature ranges are generally larger in valleys than over plains, and the vertical structure of the lower atmosphere in valleys is very different from that usually found over the plains (de Franceschi et al. 2003; Rampanelli and Zardi 2004; Rotach and Zardi 2007). Moreover, cooling rates in valleys are usually higher than those over flat areas, due to cold air flowing down the slopes to the valley floor after sunset. As a result, thermal inversions are generally stronger in valleys than over the adjacent plains (De Wekker and Whiteman 2006).

Wanner and Hertig (1984), who examined both small and midsized Swiss cities, analyzed the possible interactions between these phenomena and urban areas, emphasizing in particular the important influence of local winds. This aspect was also analyzed in detail by Kuttler et al. (1996), who highlighted how the penetration of cold-air drainage flow inside the urban canopy is a key factor affecting the development of the nocturnal UHI. Kuttler et al. (1996) found that in Stolberg — a small city in a narrow valley in western Germany-the obstruction of the built-up area, and the narrow valley cross section, block the penetration of the drainage flow into the inner city in the early evening, leading to the development of a strong UHI at this time. On the other hand, during the latter part of the night, the drainage flow is partly able to penetrate the most densely urbanized area, thus lowering the UHI effects. However, the authors concluded that the majority of the cold air flows around or over the town center, rather than penetrating into it. Kuttler et al. (1998) presented a similar analysis on the nighttime penetration of cold air in the inner city of Cologne, Germany, at the northern end of the Rhine Valley. In that case only the onset of the down-valley wind at 0100 LST was effective in producing an appreciable cooling in the urban area.

The Austrian city of Graz, in the Mur Valley (southeastern Alps), was analyzed by Piringer and Baumann (1999) and by Lazar and Podesser (1999). They pointed out that both the complex topography of the valley and the presence of the urban area contributed to the remarkably heterogeneous temperature and wind fields, along with strong ground-based thermal inversions. The latter are an important aspect for the climate of a valley city, especially if the urban area spreads onto the sidewalls, and thus topographic and urbanization effects may interact (Goldreich 1984).

In the present paper the intensity of the UHI in the city of Trento, in the Alpine Adige Valley, has been investigated by evaluating the differences $\left(\Delta T_{u-r}\right)$ between air temperature taken at an urban automated weather station placed on a tower, over the mean rooftop level $\left(T_{u}\right)$, and at five suburban-rural weather stations $\left(T_{r}\right)$, located a few kilometers outside the city boundaries (Fig. 1). Data from five extraurban weather stations were used, so as to provide more complete information on the temperature distribution all around the city. On the other hand, only one weather station was taken as representative of the inner-city urban environment, as the latter is rather small and may be reasonably represented by this weather station. As a preliminary test to assess the latter statement, data were compared with those taken at another weather station, operated by the local fire station and located on another tower north of the city center, and temperature measurements at the two urban locations were found to be very similar. 


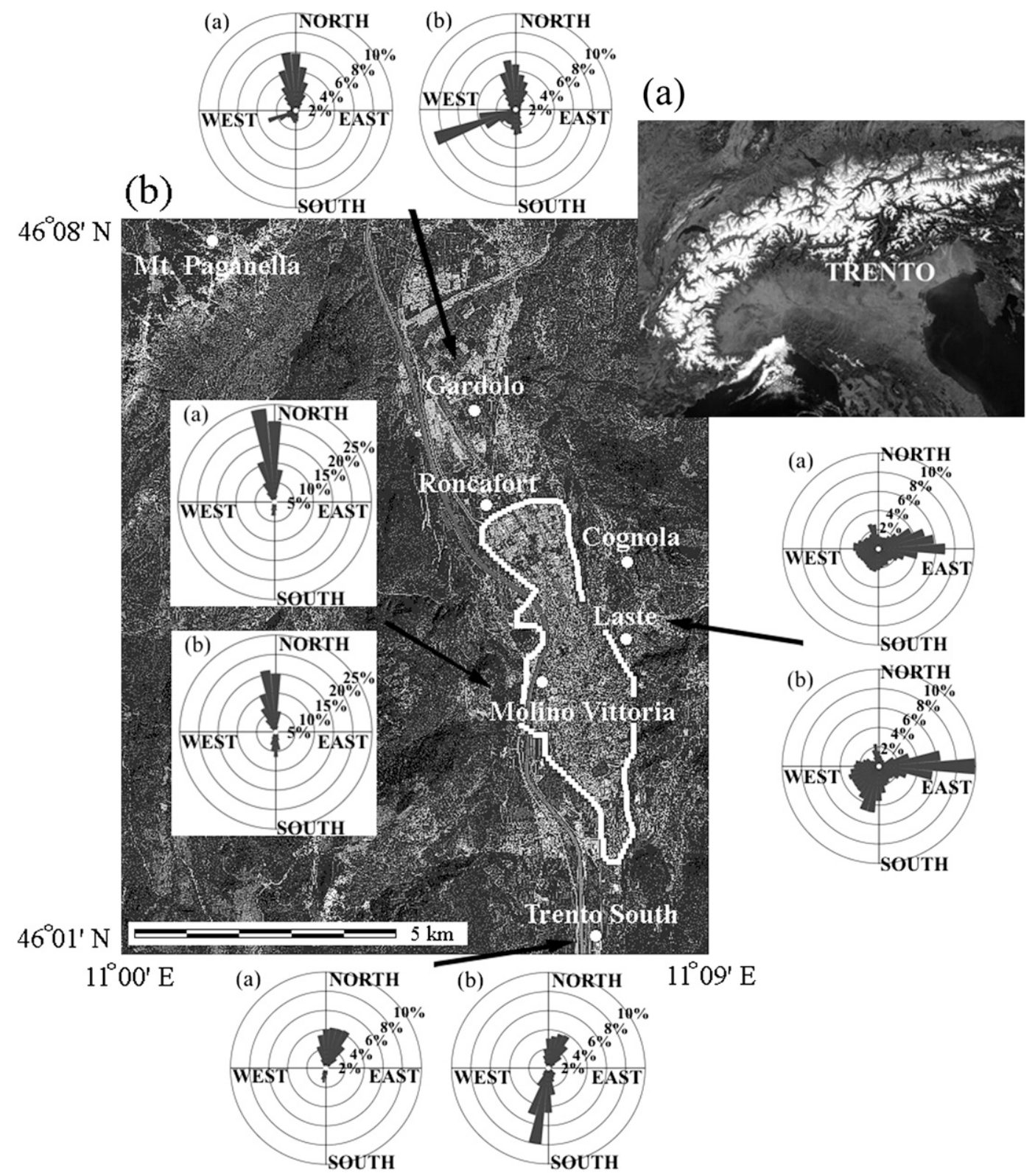

FIG. 1. Location of Trento in (a) northern Italy and (b) the Adige Valley. White bullets indicate the weather stations analyzed in this study. The white boundary encloses the area of Trento more uniformly urbanized, excluding the suburbs. The wind roses refer to the stations indicated by the arrows and cover, respectively, during (a) the cold semester (September-February) and (b) the warm semester (March-August).

One might question whether urban temperatures taken here slightly above the mean roof level are comparable with extraurban measurements taken by stations at ground level. Indeed, this mismatch might partly compromise the significance of the comparisons and, in particular, might not allow one to draw conclusions about the intensity of the canopy layer UHI (Oke 1976). To clarify this issue, two field measurements were performed in summer (26 July-20 August 2007) and in winter (23 December 2008-22 January 2009) in an urban canyon located $200 \mathrm{~m}$ from the urban weather station, to evaluate the possible temperature differences between the tower and the canopy layer. The urban canyon, which had a north-south orientation, displays an aspect ratio of about 0.85 and was instrumented with portable low-cost thermohygrometers (HoBo H8 Pro, Onset, Inc., Bourne, Massachusetts). It was found that the average temperature inside the urban canyon was only slightly higher than at the tower, both in summer and in winter. In particular, during the summer field measurements, both minima and 
maxima in the urban canyon were less than $1^{\circ} \mathrm{C}$ higher than at the reference weather station. Moreover, in winter, differences were reduced to $0.5^{\circ} \mathrm{C}$ for minima and to less than $0.5^{\circ} \mathrm{C}$ for maxima. Only the instruments placed near a sunlit wall showed a major overheating with respect to the tower, but only due to their particular collocation, (i.e., close to the thermal boundary layer of the wall), and they were hence not representative of the street environment. Following these results, we concluded that the tower station can be used as a reliable substitute for the missing ground-level stations in the city of Trento to get a reasonable estimate of UHI effects, leading eventually to only a slight underestimation of the canopy layer UHI. As a consequence, the present analysis substantially conforms to the requirements set forth by the recent systematic review provide by Stewart (2010). Notice that use of urban weather stations on top of towers seems to be quite a common situation in Italy: similar comparisons between an urban weather station placed above roof level and surface rural weather stations were performed by Colacino and Lavagnini (1982) and Bacci and Maugeri (1992) for the analysis of the UHI in Rome and in Milan, respectively. A similar mismatch in the height of urban and rural weather stations can be found also in Schmidlin (1989), who analyzed the UHI of Toledo, Ohio, and in Zauli Sajani et al. (2008), who evaluated the bioclimatic conditions in the city of Bologna, Italy. In the latter work, urban data taken above roof level were compared with measurements in a street canyon nearby, to support the meaningfulness of the comparisons with surface rural data.

This paper is organized as follows. In section 2, Trento and its particular geographic and meteo-climatological characteristics are presented, and in section 3 the weather stations and the dataset used for the analysis of the UHI are described. The results obtained are shown in section 4 , and in section 5 some conclusions are drawn along with an outlook for future development.

\section{Study area}

Trento $\left(46^{\circ} 4^{\prime} \mathrm{N}, 11^{\circ} 7^{\prime} \mathrm{E}\right)$ lies at $200 \mathrm{~m}$ MSL in the Adige Valley, which is the southern stretch of the main geographic corridor running approximately in the southnorth direction on the Italian side of the Alps (Fig. 1), and connecting the Po Plain to the Brenner Pass. A population of about 56000 lives in the inner city of Trento, whereas there is a total of about 114000 inhabitants when all the surrounding suburbs are included (Municipality of Trento 2009). In fact in the last 20 years the city has grown, especially in the northern area, and incorporated some smaller urban conglomerations that had previously existed as suburbs. As a consequence, today the surrounding area of the old city look like a single, continuously built-up area, spreading out by about $10 \mathrm{~km}$ along the valley and all across the valley width, which is about $2 \mathrm{~km}$ all the way along the valley except at the center of the urban area, where it narrows to about $1 \mathrm{~km}$ by the Doss Trento, a hill about $100 \mathrm{~m}$ high above the valley floor. The latter is practically flat, with the only exception being the riverbeds of the River Adige and its tributaries, namely the Fersina Creek, which flows inside the urban area, and the Avisio Creek, flowing into the Adige $10 \mathrm{~km}$ north of the city center (Fig. 2). The valley is flanked on the western side by Mount Bondone (2098 m MSL) and on the eastern side by Mount Marzola (1738 m MSL). Two other prominent massifs surrounding the city are Mount Paganella (2125 m MSL), northwest of the city, and Mount Vigolana (2150 m MSL), southeast of the urban area. The valley sidewall on the west is rather steep, whereas on the east it rises gently; for this reason the hills east of Trento are more intensely urbanized. Several narrow tributary valleys or gullies join the Adige Valley in the area surrounding Trento: Rio Vela Gully and Rio Gola Valley west of the city, and Fersina Gully east of Trento. A more important tributary valley (Lakes Valley) ends in the Adige Valley northwest of Trento through an elevated saddle about $400 \mathrm{~m}$ above the Adige Valley floor.

The climate of Trento displays an annual temperature range of about $20^{\circ} \mathrm{C}$, with cold winters and relatively hot summers. Average seasonal temperature values for the weather stations analyzed in this work (see section 3 ) are shown later (Table 2). In the wintertime, especially during clear nights, strong thermal inversions frequently occur over the Adige Valley floor, which can persist for a whole day or longer. This is a consequence of the weaker solar radiation input, determined not only by shorter day length and solar declination, but also by the reduced sky-view factor (cf. Grigiante et al. 2011) and the low-level cooling at the valley floor favored by nocturnal drainage winds. The average annual precipitation total is $940 \mathrm{~mm}$ (Sadler and Bellin 2004), and most of it occurs from April to November, while winters are usually quite dry. Summertime precipitation is mostly produced by short and strong convective rainstorms. The area surrounding Trento is known in the literature for its specific local circulations associated with the development of peculiar local valley winds, which occur mainly in spring and summer (Pollak 1924; Schaller 1936; Wagner 1938; de Franceschi et al. 2002). In these seasons, especially during sunny days, a well-developed local wind system occurs, consisting of a light down-valley wind during the nighttime, lasting until early morning, and a stronger up-valley wind in the afternoon and evening. The daytime up-valley wind interacts with a local wind system, the so-called ora del 
Garda, blowing from the Lakes Valley and reaching the Adige Valley through the elevated saddle northwest of Trento. For this reason, following the ora del Garda outbreak into the Adige Valley, in the early afternoon the wind direction in the middle of the valley north of Trento rapidly turns from its previous direction of $180^{\circ}$ (normal up-valley wind) to $270^{\circ} \mathrm{N}$, becoming stronger and persistent until a couple of hours after sunset (de Franceschi et al. 2002). During the cold season, winds are usually weak, excluding some cases of strong synoptic winds, which usually blow from the north and are mainly related to föhn episodes. To better characterize this complex interaction of wind systems in the area surrounding Trento, wind roses were obtained from wind direction data, covering the time period 2003-08 and taken from four meteorological stations. The four stations are located, respectively (Fig. 1), north of the city (Gardolo), inside the urban area (Molino Vittoria), south of Trento (Trento South), and on the sidewall east of the city (Laste) (see also section 3 for more details). The emerging dominant features are winds mainly blowing from north at all stations on the valley floor during the cold season (i.e., autumn and winter), while in the warm season (i.e., spring and summer) southerly winds (up valley) become stronger. The wind rose at Gardolo clearly shows a prevailing direction from west-southwest in the warm season, due to the interaction with the above-mentioned ora del Garda. The presence of downslope winds is evident in the wind rose at Laste, during both cold and warm seasons, whereas the upslope direction is less frequently observed.

\section{Measurement sites}

To investigate the thermal structure and the UHI intensity of the city, a dataset of surface air temperature measurements was composed from data collected at six automated weather stations, routinely operated at different sites within or around the urban area (Fig. 1). The first station, hereinafter identified as Molino Vittoria, is close to the city center and, as anticipated, is assumed to be representative of the inner urban area. It was installed in October 2002, on the roof of a tower in a building named Molino Vittoria (33 m AGL), and has been operated continuously since by the Atmospheric Physics Group of the University of Trento (de Franceschi and Zardi 2007). The data recorded at this location, and used for the present analysis, are 10-min-average values of air temperature, wind speed, and global radiation (information online at www.ing.unitn.it/ prometeo/home.htm). The station is close to the western boundary of the city center, whose core is built over the old-Roman-traced city, displaying a typical regular grid of narrow streets, crossing at right angles, and oriented either north-south or east-west.
The average building height in the city center is about $15-20 \mathrm{~m}$ and the aspect ratio of the main streets is about 1 , while many narrower alleys display higher values. In this area the vegetation is very sparse or totally absent, the building walls are covered with plaster, while the ground surface is covered with asphalt. This compact urban area surrounds the weather station in all the sectors from northeast to southeast, whereas to the west of the station the city is less compact: there is a parking lot covered by asphalt, and farther west, about $200 \mathrm{~m}$ from the station, the Adige River, close to the steep slope bounding the valley on the western side. Since the local circulation pattern displays a rather poor occurrence of westerly winds (Fig. 1), it can be inferred that the measurement station is mainly influenced by rather homogeneous surfaces, which are representative of the urban area. To substantiate this assumption with an objective and quantitative characterization of the urban morphology around the station, the building plan area fractions $\lambda_{p}=A_{p} / A_{t}$ (where $A_{p}$ is the plan area of buildings and $A_{t}$ is the total area) were calculated for the area. To this purpose, the Digital Terrain Model and the Digital Elevation Model data, calculated on the basis of airborne lidar scans, were obtained from the Municipality of Trento. The above models provide an accuracy of $1 \mathrm{~m}$ in the horizontal and $0.15 \mathrm{~m}$ in the vertical. The city center, east of the weather station, displays rather high values of $\lambda_{p}$ ranging from 0.5 to 0.8 . Lower values, of order 0.2 , were found west of the tower over the parking lot and the Adige River. Furthermore, an estimate of the source area of the urban weather station was also performed, based on the parameterization proposed by Kljun et al. (2004), by means of a freely available online tool (http://footprint.kljun.net/). The source area was found to fall inside the quite homogeneous urban area described above, for a reasonable range of the parameters used by the parameterization.

The remaining five weather stations are located in suburban or rural areas around the city, and temperature measurements are taken at $2 \mathrm{~m}$ AGL there. These stations will be identified from the name of their sites. Three extraurban weather stations belong to an agrometeorological network, operated by the Institute for Agriculture of San Michele all'Adige, which is affiliated with the Edmund Mach Foundation. Two of these stations are located on the valley floor, respectively, north and south of Trento. The station identified as Gardolo is located in the northern countryside, and is surrounded by croplands, while the other one-Trento South-is near the city's small airport, in a green area a few kilometers south of the city. The third station, identified as Cognola, is placed on the valley sidewall east of the city, and is surrounded by croplands and a deciduous broad-leaved forest. All of these stations provide hourly average values 
TABLE 1. Summary of the weather stations along with their coordinates and altitudes, and the measurements used for the analyses presented in this paper. Here, $T=$ temperature; $R=$ global radiation; $\mathrm{WV}=$ wind velocity $; \mathrm{WD}=$ wind direction; $\mathrm{CC}=$ cloud cover.

\begin{tabular}{lcccccc}
\hline \hline & \multirow{2}{*}{$\begin{array}{c}\text { Coordinates } \\
\text { Station name }\end{array}$} & $\begin{array}{c}\text { Alt } \\
\text { (lat, lon) }\end{array}$ & & \multicolumn{2}{c}{ Measurements } \\
\cline { 5 - 8 } & (m MSL) & & $T$ & $R$ & WV & WD CC \\
\hline Molino Vittoria & $46^{\circ} 03^{\prime} \mathrm{N}, 11^{\circ} 06^{\prime} \mathrm{E}$ & 224 & $\mathrm{X}$ & $\mathrm{X}$ & $\mathrm{X}$ & $\mathrm{X}$ \\
Gardolo & $46^{\circ} 06^{\prime} \mathrm{N}, 11^{\circ} 06^{\prime} \mathrm{E}$ & 197 & $\mathrm{X}$ & & $\mathrm{X}$ \\
Roncafort & $46^{\circ} 05^{\prime} \mathrm{N}, 11^{\circ} 06^{\prime} \mathrm{E}$ & 194 & $\mathrm{X}$ & & $\mathrm{X}$ \\
Trento South & $46^{\circ} 01^{\prime} \mathrm{N}, 11^{\circ} 07^{\prime} \mathrm{E}$ & 185 & $\mathrm{X}$ & & $\mathrm{X}$ \\
Cognola & $46^{\circ} 04^{\prime} \mathrm{N}, 11^{\circ} 08^{\prime} \mathrm{E}$ & 344 & $\mathrm{X}$ & & & \\
Laste & $46^{\circ} 04^{\prime} \mathrm{N}, 11^{\circ} 08^{\prime} \mathrm{E}$ & 312 & $\mathrm{X}$ & $\mathrm{X}$ & $\mathrm{X}$ & \\
Paganella & $46^{\circ} 09^{\prime} \mathrm{N}, 11^{\circ} 02^{\prime} \mathrm{E}$ & 2125 & & & & $\mathrm{X}$ \\
\hline
\end{tabular}

of air temperature. The other two extraurban stations are operated by the Meteorological Office of the Autonomous Province of Trento, and are located, respectively, in an area dedicated to agriculture, north of the city (Roncafort), and in a suburban area on the valley slope east of Trento (Laste). This part of the sidewall is moderately urbanized, but open spaces and vegetation are also present, thus resulting in $\lambda_{p}$ values on the order of 0.2-0.3 in the area surrounding this station. Both of these stations provide 15-min-average values of air temperature.

To summarize, three of the five extraurban weather stations (Gardolo, Trento South, and Roncafort) are located, as is the urban site, on the valley floor, at about $200 \mathrm{~m}$ MSL, while the remaining two stations, Laste and Cognola, are situated on the eastern sidewall, at 312 and $344 \mathrm{~m}$ MSL, respectively (Table 1). As a consequence, since UHI intensity is evaluated by analyzing the temperature differences between the urban site and each of these stations, the results may reflect both effects due to topographic features and to urbanization. This question was previously faced by Lowry (1977), who pointed out that the climate of a particular location is given by the sum of three components: the "background" climate, and the effects of the total landscape and of local urbanization. Therefore, when evaluating UHI intensity by analyzing temperature differences between "urban" and "rural" weather stations, it is implicitly assumed that the background climate and the landscape effects are identical at the two locations. This assumption is not easily met in complex terrain, where the overall landscape effects may vary significantly over space scales as short as a few kilometers, for example, due to the varying topography or to particular microclimatic features, closely related to complex terrain characteristics (e.g., slope winds). In the present case, it is reasonable to assume, at least as a first approximation, that the weather stations located on the valley floor are affected by similar landscape effects as the urban station. Therefore, temperature differences
TABLE 2. Average seasonal temperatures $\left({ }^{\circ} \mathrm{C}\right)$ measured at the six weather stations taken into account for the evaluation of the UHI.

\begin{tabular}{lcccc}
\hline \hline Station name & Winter & Spring & Summer & Fall \\
\hline Molino Vittoria & 2.61 & 12.69 & 22.99 & 12.84 \\
Gardolo & 1.62 & 12.14 & 22.22 & 12.01 \\
Roncafort & 1.22 & 11.89 & 22.03 & 11.65 \\
Trento South & 1.67 & 12.19 & 22.63 & 12.22 \\
Cognola & 1.24 & 11.13 & 21.39 & 11.46 \\
Laste & 2.37 & 11.85 & 22.08 & 12.32 \\
\hline
\end{tabular}

between the urban weather station and these locations can be interpreted as urbanization effects. On the contrary, Cognola and Laste, because of their different altitudes in comparison with the urban site, are influenced by landscape effects, which are slightly different from Molino Vittoria. For this reason it may be argued that the location of these two weather stations may not be an optimal one for the evaluation of UHI intensity. On the other hand, their measurements specifically reflect phenomena actually occurring on this urbanized sidewall, and a comparison between the urban site and the suburban weather station of Laste will provide information about the interaction between topography and urbanization (Goldreich 1984, 2009). Moreover, the comparison between the Laste and Cognola temperature datasets can be useful when evaluating thermal differences between a suburban and a rural area that are roughly at the same altitude.

To compensate for topographic effects, some authors used potential temperature (Oke and East 1971) or vertical profiles with constant lapse rates (Nkemdirim 1980; Junk et al. 2003). However, such an approach does not take into account that the actual lapse rate is not constant and may change, not only on a seasonal basis, but also from day to day (Goldreich 1984). In the present case topographic effects affecting temperature differences between the valley floor and the weather stations on the sidewalls can be evaluated, at least as a first approximation, by comparing the average seasonal temperatures (Table 2) at the three weather stations on the valley floor and at Cognola. All of them are in the countryside, so they may be weakly affected by urbanization. Topographic differences turn out to be on average on the order of $0.6^{\circ}-$ $0.7^{\circ} \mathrm{C}$, being stronger in spring and summer and weaker in fall and winter. These results support the relevance of frequent ground-based thermal inversions during the cold season in reducing topographic effects. Following these considerations, in the present study UHI intensity has been evaluated using the actual air temperature, but the topographic effects estimated above have been taken into account in the interpretation of the results of the extraurban weather stations placed on the valley sidewalls.

The dependence of UHI intensity on wind speed and cloud amount has also been analyzed. For this purpose, 
TABLE 3. UHI average intensity $\left({ }^{\circ} \mathrm{C}\right.$; calculated as the difference between Molino Vittoria and the five extraurban stations) during the full day and separated into daytime and nighttime. Here, $N$ indicates the number of temperature data pairs, $T_{u}$ and $T_{r}$, used to evaluate the mean difference, $\Delta T_{u-r}=T_{u}-T_{r} ; \sigma$ indicates the standard deviation.

\begin{tabular}{|c|c|c|c|c|c|c|c|c|c|}
\hline \multirow[b]{2}{*}{ Station name } & \multicolumn{3}{|c|}{ All day } & \multicolumn{3}{|c|}{ Daytime } & \multicolumn{3}{|c|}{ Nighttime } \\
\hline & $N$ & $\Delta T_{u-r}$ & $\sigma$ & $N$ & $\Delta T_{u-r}$ & $\sigma$ & $N$ & $\Delta T_{u-r}$ & $\sigma$ \\
\hline Gardolo & 53359 & 0.76 & 1.61 & 29415 & 0.03 & 1.30 & 23944 & 1.67 & 1.49 \\
\hline Roncafort & 42704 & 1.07 & 1.50 & 23391 & 0.49 & 1.24 & 19313 & 1.79 & 1.47 \\
\hline Trento South & 53304 & 0.58 & 1.35 & 29427 & -0.06 & 1.03 & 23877 & 1.37 & 1.27 \\
\hline Cognola & 52849 & 1.48 & 1.56 & 29153 & 0.74 & 1.47 & 23696 & 2.39 & 1.13 \\
\hline Laste & 50288 & 0.65 & 1.07 & 27827 & 0.54 & 1.20 & 22461 & 0.79 & 0.88 \\
\hline
\end{tabular}

wind speed data from routine measurements at Molino Vittoria (10-min average) were used, while hourly cloud cover observations (in oktas) were taken from the Mount Paganella weather station. The latter is operated by the Meteorological Service of the Italian Air Force, $10 \mathrm{~km}$ northwest of Trento, at $2125 \mathrm{~m}$ MSL. Despite the high altitude, these cloud-cover observations are fairly well representative of the weather conditions over the city in most of the cases.

The station at Molino Vittoria is the most recently installed site (October 2002), and this date sets the starting time for the whole dataset, which covers the period October 2002-December 2008. Finally, we note that, for the sake of consistency with the rest of the dataset, data from observations at Molino Vittoria, Roncafort, and Laste were downsampled to hourly averages.

\section{Data analysis}

\section{a. Average values of the UHI}

As a first step, an average UHI intensity was evaluated by comparing all the hourly mean temperature values from Molino Vittoria (city center) with the corresponding values of the five extraurban weather stations.

Results from these comparisons are shown in Table 3. On the valley floor the average urban-rural temperature differences range between $0.6^{\circ}$ and $1.1^{\circ} \mathrm{C}$. Such values are quite small, compared to typical UHI intensities found in larger cities. However, these average temperature differences include every weather condition and every hour of the day, whereas, as shown below, UHI intensity is strongly dependent on these factors, as can be argued from the high values of the standard deviations (Table 3 ). As a consequence, the above values should be considered only a preliminary and partial representation of the UHI effect. Moreover, the UHI intensity inside the canopy layer is likely to be slightly higher than that resulting from the tower station measurements, due to the factors mentioned in section 1 . The appreciable differences found between the average UHI intensities at the three rural weather stations on the valley floor are not easily explained. They can be caused by slightly different landscape effects, or by a partial influence of urbanization on the areas surrounding these weather stations.

As to the two weather stations on the valley slopes, average temperature contrasts with the urban site are $0.7^{\circ}$ and $1.5^{\circ} \mathrm{C}$ at Laste and Cognola, respectively. It is interesting to notice that the average temperature difference between the two stations on slopes, one suburban and one rural, is comparable to those found between the urban and the rural weather stations located on the valley floor. Assuming that these two stations are affected by similar topographic effects, this fact suggests that urbanization has considerable influence on Laste. Indeed, the average temperature difference between Molino Vittoria and Laste is of the same order of magnitude as the topographic effects estimated in section 3 .

\section{b. Diurnal-cycle variations of the UHI}

The dataset was split into a daytime and a nighttime subset (simply identified on the basis of incoming solar radiation detected by the radiometer at Molino Vittoria), in order to evaluate separately the average intensities of the UHI during the two parts of the day. Based on the analysis of these subsets, three main aspects can be outlined (Table 3).

First, UHI intensity appears to be stronger during the night at the rural weather stations, following the wellestablished concept that urban-rural temperature differences are higher during the nighttime (Oke 1987). For the three weather stations on the valley floor, nocturnal urbanrural temperature contrasts seem to be slightly stronger in the countryside north of the city than south of it. However, the temperature differences with the urban site are quite similar at these three weather stations, on the order of $1.5^{\circ} \mathrm{C}$. The highest temperature difference with the urban site, among the five extraurban weather stations, is found at Cognola $\left(2 \cdot 4^{\circ} \mathrm{C}\right)$. However, part of this difference has to be attributed to topographic effects.

Second, it seems that during the daytime, on average, urbanization effects do not significantly affect urban-rural temperature differences. Considering the three weather 


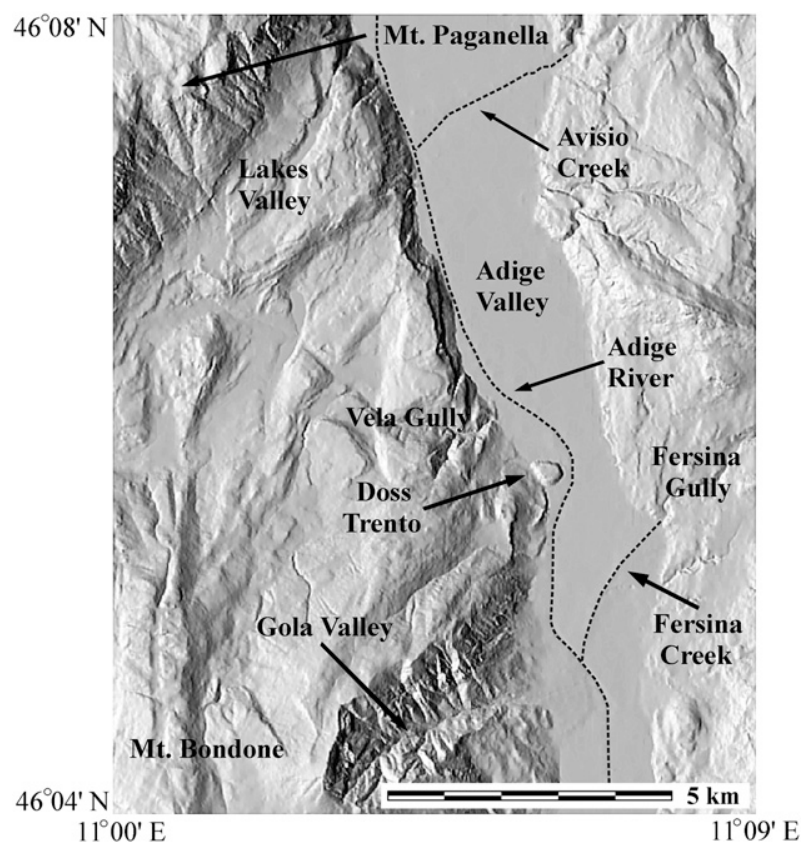

FIG. 2. Digital Terrain Model of the area shown in Fig. 1b, representing Trento and its surroundings, including the Adige Valley and its sidewalls.

stations located on the valley floor, the average temperature differences with the urban site during daytime are negligible at Gardolo and Trento South and low $\left(\sim 0.5^{\circ} \mathrm{C}\right)$ at Roncafort. On the other hand, the value obtained at Cognola $\left(0.7^{\circ} \mathrm{C}\right)$ can be almost completely attributed to the altitude difference.

Third, concentrating on Laste, the temperature contrasts with Molino Vittoria are very similar during the daytime and nighttime. Indeed, the temperature diurnal cycle at this station is similar to that registered at the urban site, confirming the strong influence of urbanization on the surrounding area. The same conclusion can be drawn by observing that during both the daytime and nighttime the average temperature differences with Cognola are similar to urban-rural contrasts found on the valley floor.

The diurnal cycle of the UHI can be better understood by analyzing its intensity on an hourly basis. In Fig. 3a a box plot of the hourly intensity of the UHI is shown, with respect to the rural Gardolo station, whose behavior was found to be similar to the other rural stations on the valley floor (not shown). It can be seen, as highlighted above, that UHI intensity is stronger at night, whereas urban-rural temperature differences progressively decrease in the morning. During the central hours of the day, when solar radiation is stronger, the temperature at the urban site becomes on average even lower than at the rural weather station, with the development of an urban (a)

Gardolo

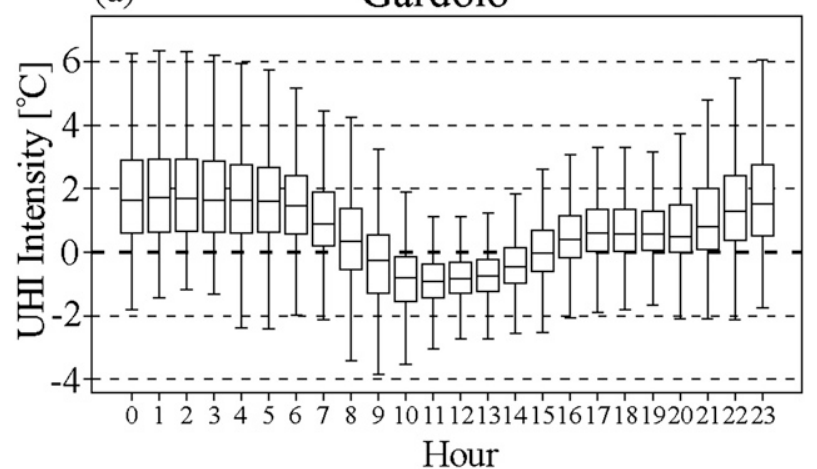

(b)

\section{Cognola}

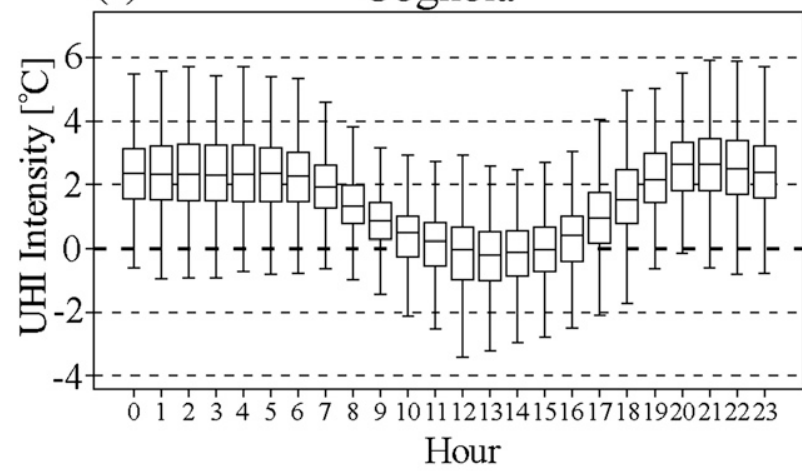

(c)

Laste

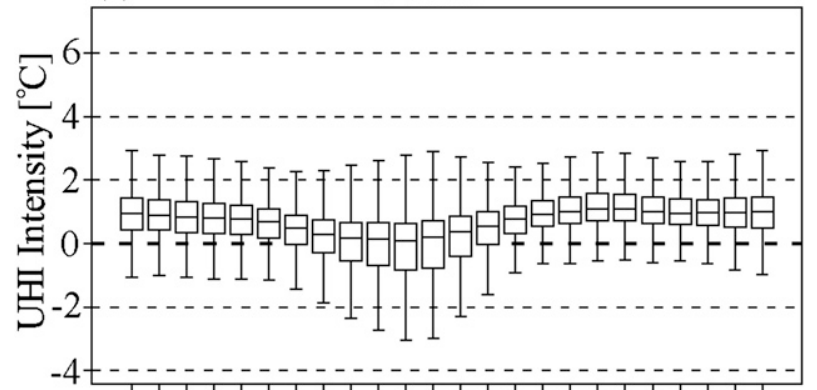

$\begin{array}{lllllllllllll}0 & 1 & 2 & 3 & 4 & 5 & 6 & 7 & 8 & 9 & 1011121314151617181920212223\end{array}$

Hour

FIG. 3. Box plots of hourly temperature differences between Molino Vittoria and (a) Gardolo, (b) Cognola, and (c) Laste. The bottom and the top of the boxes represent, respectively, the first and the third quartiles $\left(Q_{1}\right.$ and $\left.Q_{3}\right)$, while the line in the middle is the median $\left(Q_{2}\right)$. The ends of the whiskers represent, respectively, the lowest datum still within $Q_{1}-1.5\left(Q_{3}-Q_{1}\right)$ and the highest datum still within $Q_{3}+1.5\left(Q_{3}-Q_{1}\right)$. This description applies to all the box plots shown in this paper.

cool island. In fact, especially during the morning, urban surface materials, typically displaying a higher thermal admittance, store a large amount of heat and therefore urban areas warm up more slowly than does the nearby countryside (Oke 1987). The development of an urban cool island is a phenomenon observed in several cities of different sizes and with different climates. For instance, 
Lee and Baik (2010) found an urban cool island in Seoul, South Korea, in $77 \%$ of the nonprecipitating days in spring, while Unwin (1980) reported an average cool island of $0.49^{\circ} \mathrm{C}$ in Birmingham, United Kingdom. Furthermore, Steinecke (1999) found a strong urban cool island in Reykjavik, Iceland, in summer, due to the low solar altitude and the consequent overshadowing inside the urban area. In the present case the urban cool island develops mainly between 1000 LST (UTC $+1 \mathrm{~h}$ ) and 1300 LST, when intensities higher than $1.5^{\circ} \mathrm{C}$ can be reached.

However, the field measurements inside the urban canyon suggest that the intensity of the urban cool island is likely to be very weak during the summer period in the canopy layer, whereas a rather stronger effect probably occurs even at ground level during the wintertime, especially in the more compact areas, due to an overshadowing effect. This suggests that the compactness of the city center may play an important role in the development of an urban cool island in Trento.

The heat stored is then released after sunset, when the temperature in the city drops slower than in the countryside, thus resulting in higher nocturnal temperatures inside the urban area. As found by Morris and Simmonds (2000), UHI intensity is roughly constant during the night, from 2300 to $0600 \mathrm{LST}$, and in the case of Trento the average value turns out to be, as seen above, of order $1.5^{\circ} \mathrm{C}$. Nevertheless, during these hours remarkable differences between urban and rural areas are reached; indeed, the value of the third quartile is about $3^{\circ} \mathrm{C}$, which means that in one night out of four the temperature in the city is almost $3^{\circ} \mathrm{C}$ higher than in the countryside. Thus, in contrast with the conclusions of Kuttler et al. (1996) for the valley city of Stolberg, in Trento the UHI intensity is rather constant during the night. This finding is supported by the fact that usually at Molino Vittoria a rather strong and persistent down-valley wind blows for the whole night (not shown here), and therefore there is no evidence that the penetration of cold-air drainage flow in the inner city is hindered in the early evening by the obstruction of the built-up area. However, this finding may not be fully representative of processes occurring at ground level within the built-up area, as far as the urban weather station is placed well above the urban canopy layer, as discussed in section 1 .

At Cognola (Fig. 3b), the behavior of the diurnal cycle of the UHI is similar to that found on the valley floor, but in this case the maximum differences from the urban site are reached in the evening, probably because the drainage flow reaches the sidewalls earlier than the valley floor.

From the box plot for the Laste weather station (Fig. 3c), it can be seen that, as expected, the temperature differences with the urban site are less variable throughout the day in comparison with the rural stations. However, the overall pattern of behavior is similar, with minimum

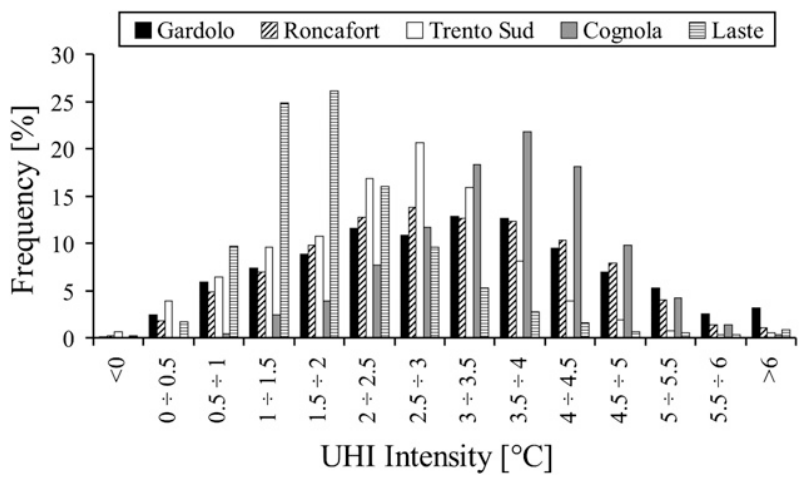

FIG. 4. Frequency distribution of the diurnal maximum intensity of the UHI on an hourly basis for the five extraurban weather stations as indicated.

differences in the morning and maximum UHI intensity during the late afternoon and at night.

The height of the boxes and the length of the whiskers in the box plots in Fig. 3, provide an estimate of the scatter in the hourly data. At Gardolo the maximum spread around the median value is observed at night, while at Laste it is found during the daytime. At Cognola the dispersion in the hourly data is roughly constant throughout the day. Thus, on the valley floor the temperature differences from the urban site are expected to be more affected at night than during the daytime by factors such as weather conditions or the season. The opposite pattern of behavior is expected at Laste.

\section{c. Diurnal maximum UHI intensity}

The frequency distribution of the diurnal maxima of UHI intensity, computed on an hourly basis, is shown in Fig. 4. Considering the extraurban weather stations lying on the valley floor, the maximum differences with the urban site range between $2^{\circ}$ and $4^{\circ} \mathrm{C}$ on more than $50 \%$ of the days. Higher values more often occur at Gardolo and Roncafort, in the northern countryside, than south of the city at Trento South. At Laste, the maximum diurnal differences with the urban site fall most frequently between $1^{\circ}$ and $2^{\circ} \mathrm{C}$. Values higher than $3^{\circ} \mathrm{C}$ are rarely reached. At Cognola, the most frequent values of the diurnal maximum $\mathrm{UHI}$ intensity range between $3^{\circ}$ and $5^{\circ} \mathrm{C}$.

Figure 5 shows a histogram of the frequency distribution of the local time of occurrence of the diurnal maxima of the UHI intensity, confirming the results obtained from the analysis of the diurnal cycle of the UHI. At the rural locations on the valley floor the diurnal maximum UHI intensity is observed most often in the middle of the night. The same analysis for the sidewall weather stations shows that the maximum occurrence is reached in the afternoon (between 1400 and 1800 LST) at Laste but some hours later (between 1800 and 2200 LST) at Cognola. 


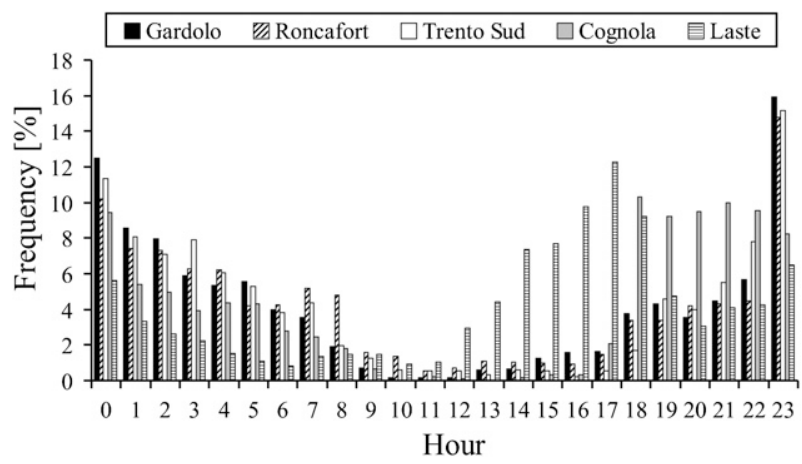

FIG. 5. Frequency distribution of the local time of occurrence of the diurnal maximum intensity of the UHI for the five extraurban weather stations as indicated.

\section{d. Seasonal variations of the UHI}

To evaluate the seasonal variations of the UHI intensity, temperature differences between the urban site and the extraurban weather stations were compared on a monthly basis. Following the different features characterizing the daytime and nighttime phases of the UHI, as outlined in section $4 \mathrm{~b}$, it seems convenient to analyze separately these two subsets.

Figure 6 shows the yearly cycles of the daytime UHI intensity at Gardolo (which is also representative of the other two extraurban stations on the valley floor), and at Cognola (whose pattern of behavior is analogous to that found at the other sidewall station). At Gardolo, the urbanrural temperature differences are quite constant throughout the year. On the other hand, taking into account Cognola, a completely different yearly cycle can be seen: maximum UHI intensities are reached during summer months, while the lowest differences are recorded during the wintertime. This can be explained by observing, as discussed in section 3, that in the Adige Valley the mean lapse rate is lower during the cold season than in the summer months, partly due to the frequent thermal inversions in winter; hence, the average temperature differences between the urban station, located on the valley floor, and those lying on the valley sidewalls are smaller.

The yearly cycle of the nocturnal UHI intensity (Fig. 7) shows that maximum intensities are reached at Gardolo during the winter and summer months, while there are smaller differences in spring and in October. These results are consistent with the findings of Jauregui (1987) and Kim and Baik (2002): UHI intensity is stronger during dry periods, when conditions favorable to developing strongly different cooling rates between rural and urban areas are more likely to occur. In fact, as recalled above, spring and autumn are the rainiest seasons in Trento, while during the wintertime frequent and persistent anticyclonic situations inhibit precipitation. The nighttime and daytime (a) Gardolo

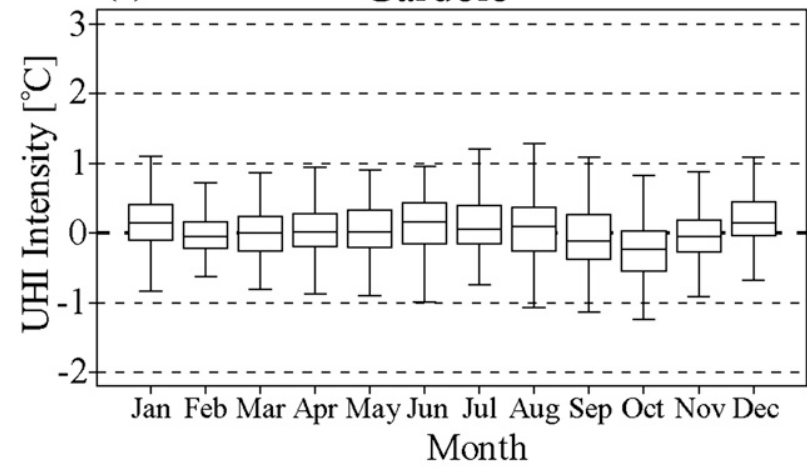

(b)

Cognola

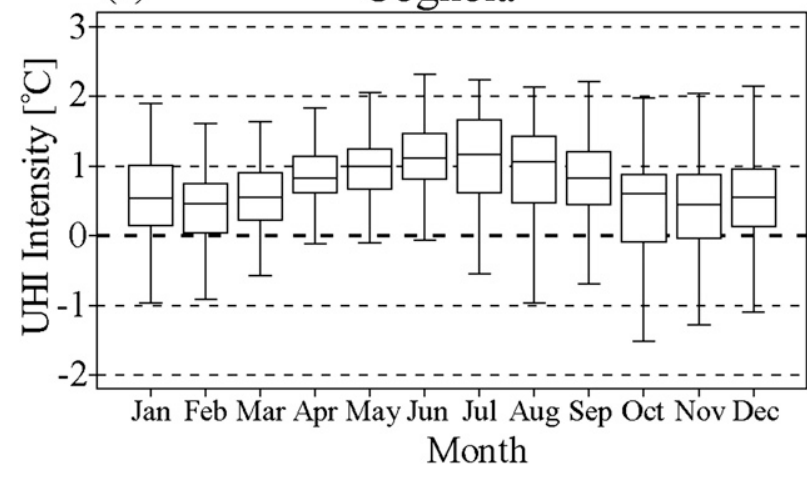

FIG. 6. Box plots of daytime monthly temperature differences between Molino Vittoria and (a) Gardolo and (b) Cognola.

yearly cycles at Cognola are very similar, with maximum UHI intensities in summer, and minimum values during the winter.

\section{e. Evaluation of cloud-cover effects}

As a further step in the evaluation of UHI effects at Trento, the possible dependence on cloud cover has been investigated, grouping the data into five classes, based on cloud-cover observations at the Mount Paganella weather station. This analysis was carried out on an hourly basis, so as to characterize the influence of cloud cover on the diurnal cycle of the UHI.

Figure 8 shows box plots for Gardolo, which are again also representative of the other rural stations on the valley floor. The urban-rural temperature differences decrease progressively as the cloud cover increases, both during daytime and nighttime. Under clear-sky conditions urbanrural temperature differences are positive and quite strong at night, whereas in the middle of the day the temperature at Molino Vittoria is lower than at Gardolo. On the contrary, when the sky is completely cloudy, temperatures at the urban site and at Gardolo are similar for the whole day. In addition, the scatter in the hourly data tends to decrease as the cloud cover increases, especially at night. 
(a)

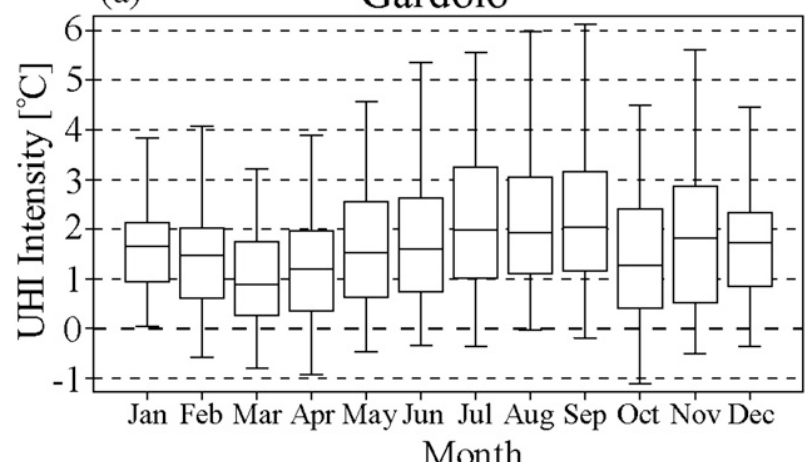

(b)

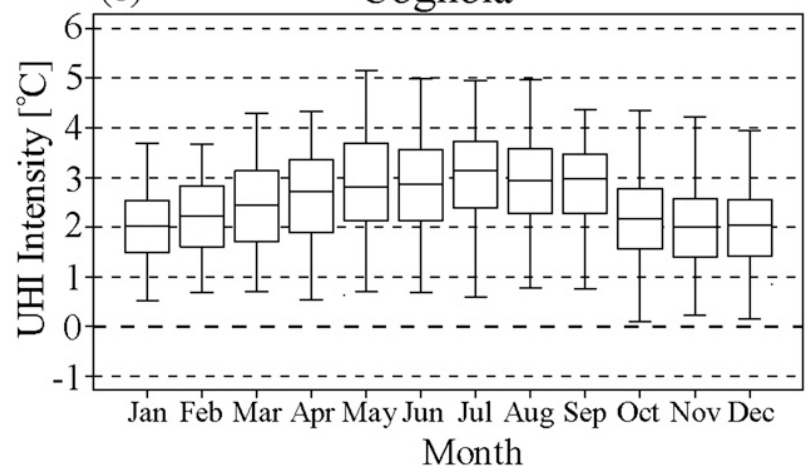

FIG. 7. As in Fig. 6, but for nighttime.

Under cloudy conditions, at any hour, half of the data ranges within $0.5^{\circ} \mathrm{C}$.

The pattern of behavior at Cognola is similar, with only minor differences (not shown). During the nighttime the UHI intensity seems less affected by cloud cover than at the rural weather stations on the valley floor, whereas during mid-day the influence of cloud cover seems stronger. To explain these trends, one should remember that temperature differences between Molino Vittoria and Cognola result from the combination of two factors, namely urbanization and topographic effects. It was found (not shown here) that temperature differences between the rural weather stations on the valley floor and Cognola become slightly stronger as cloud cover increases during both the daytime and nighttime, as thermal inversions are more frequent under clear-sky conditions. Thus, it can be argued that temperature differences between Molino Vittoria and Cognola due to topographic effects also become stronger as the cloud cover increases. On the contrary, the analysis carried out at the rural weather stations on the valley floor shows that the temperature differences between urban and rural areas due to urbanization effects decrease as cloud cover increases. Therefore, during the nighttime the two contrasting effects result in a lower influence of cloud clover on UHI intensity at Cognola than on the valley floor. On the other hand, during the central hours of the day the temperature differences due to both topographic and urbanization effects have the same pattern of behavior as the cloud cover increases, and therefore the net result is an enhanced influence of cloud cover on the temperature contrasts between the urban site and Cognola.

Also at Laste (Fig. 9) the temperature contrasts with Molino Vittoria tend to become constant throughout the day as cloud cover increases, but in this case only the temperature differences in the middle of the day seem to be affected by cloud cover since during the nighttime the UHI intensity remains roughly the same under all cloudcover conditions. Thus, the pattern of behavior found at Laste at night is different from that found at Cognola. It can be supposed that at Cognola, in a rural area, cloud cover affects the local nocturnal radiative cooling more than the lapse rate, whereas at Laste, in a suburban location, where nocturnal cooling is lower, the two contrasting effects are balanced, and therefore cloud cover does not significantly affect the temperature differences from the urban site at night. On the other hand, during the central hours of the day the temperature differences between Molino Vittoria and Laste, negative under clear-sky conditions, become positive as cloud cover increases, due to the combination of urbanization and topographic effects.

Figure 10 shows the dependence of the diurnal maximum intensity of the UHI on cloud cover for the Gardolo weather station, analyzing situations with wind speeds of less than $1 \mathrm{~m} \mathrm{~s}^{-1}$, so as to isolate the effects of cloud cover only. The maximum UHI intensity decreases roughly linearly as cloud cover increases, and from the relative scatterplot (not shown here) the statistics are a slope $=$ $-0.26^{\circ} \mathrm{C} \mathrm{okta}^{-1}$ and an intercept $=3.72^{\circ} \mathrm{C}$ (with the coefficient of determination $R^{2}=0.17$, a rather small value due to the large scatter of the data). The value of the intercept indicates the average maximum UHI in "ideal" conditions, with low wind speeds and cloudless skies. This value is lower than predicted by Oke's (1973) formula for European cities:

$$
\Delta T_{u-r}=2.01 \log (P)-4.06,
$$

where $P$ is the city population. In the case of Trento, use of the population in the inner city provides $\Delta T_{u-r}=$ $5.5^{\circ} \mathrm{C}$. From Fig. 10 it can be seen that this value is also $1^{\circ} \mathrm{C}$ higher than the third quartile under low wind speed and cloudless conditions. However, due to the high variability in the data, values higher than $5.5^{\circ} \mathrm{C}$ are possible, as can be seen by the higher whisker. Moreover, the real intensity of the canopy-layer UHI might be $0.5^{\circ}-1^{\circ} \mathrm{C}$ higher than obtained from data from the weather station above the roof level. Thus, the maximum intensity of the UHI in Trento substantially agrees with the value given by Eq. (1), as well 
(a)

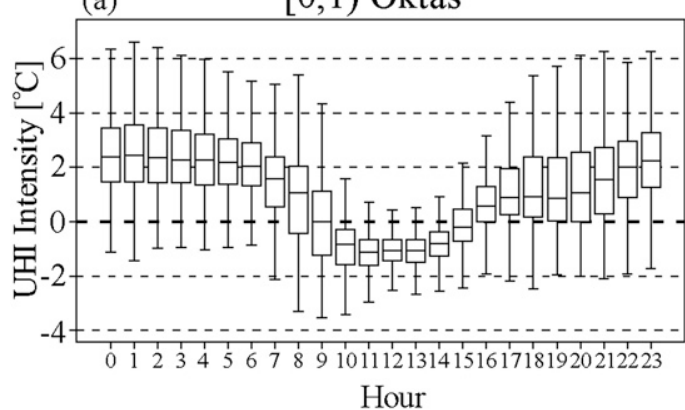

(c)

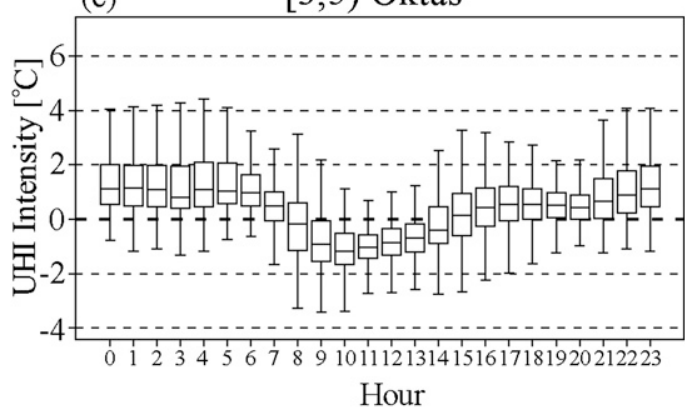

(e)

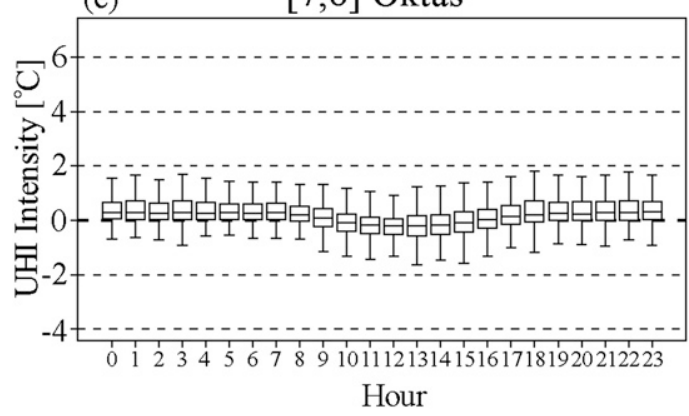

(b)

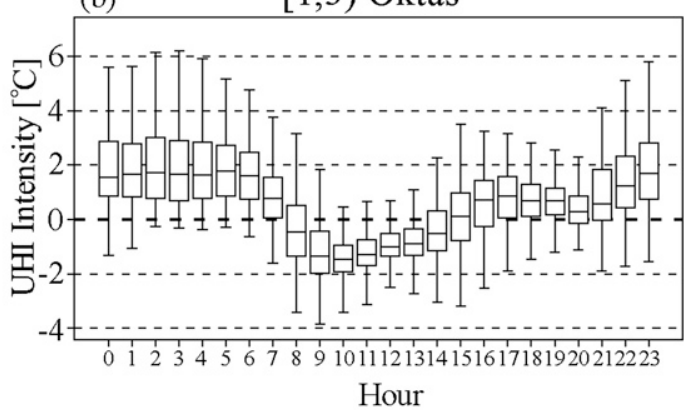

(d)

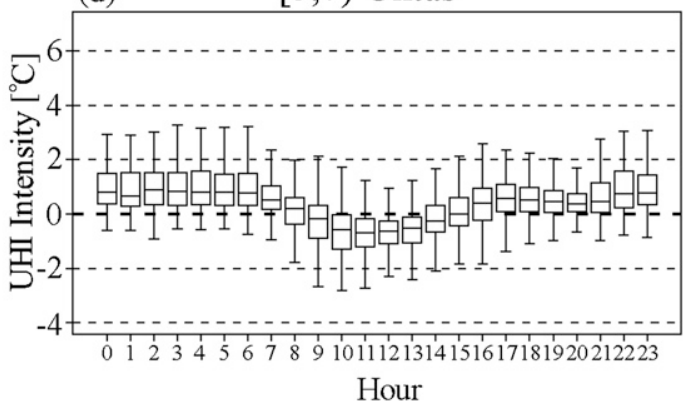

FIG. 8. Box plots of hourly temperature differences between Molino Vittoria and Gardolo classified by cloud-cover classes in oktas observed at the Mount Paganella weather station. as with the intensities reported for European cities (Oke 1973) of similar size as Trento (maximum UHI intensities ranging from $4.4^{\circ}$ to $7^{\circ} \mathrm{C}$ ). Notice that Kuttler et al. (1996) found a similar maximum UHI intensity $\left(6^{\circ} \mathrm{C}\right)$ in Stolberg (60 000 inhabitants), located, as is Trento, in a narrow valley and thus influenced by similar local conditions.

The same analysis was also carried out for the weather stations on the valley sidewall (not shown). As expected from the previous results, at Cognola the dependence of the maximum UHI intensity on cloud cover is less than on the valley floor, but still significant, whereas at Laste the influence of cloud cover is negligible.

\section{f. Evaluation of wind effects}

A further analysis has been carried out to assess the impacts of wind speed; accordingly, temperature differences with the urban site were grouped into six wind speed classes, based on wind intensities recorded at Molino Vittoria, so as to include in every class a representative number of values.
Figure 11 shows the box plots for Gardolo, on the valley floor: during the nighttime the UHI intensity tends to decrease as the wind speed increases, whereas during the daytime the urban-rural temperature differences do not seem to be significantly affected by wind speed. During the nighttime wind speed affects the UHI intensity to a smaller extent than cloud cover.

On the valley slopes the diurnal cycle of the UHI seems to be little affected by the wind speed recorded at Molino Vittoria, during both daytime and nighttime: at Cognola and Laste the diurnal cycles of the UHI remain similar to those shown in Fig. 3 in every wind condition (not shown). This finding may be attributed to the fact that wind speeds measured at Molino Vittoria are not fully representative of the conditions at the sidewalls, where local downslope winds typically occur (Fig. 1): a correlation analysis (not shown) highlighted that wind speeds at Molino Vittoria and at Laste are well correlated during daytime, whereas there is poor correlation at night, when, as found above, 

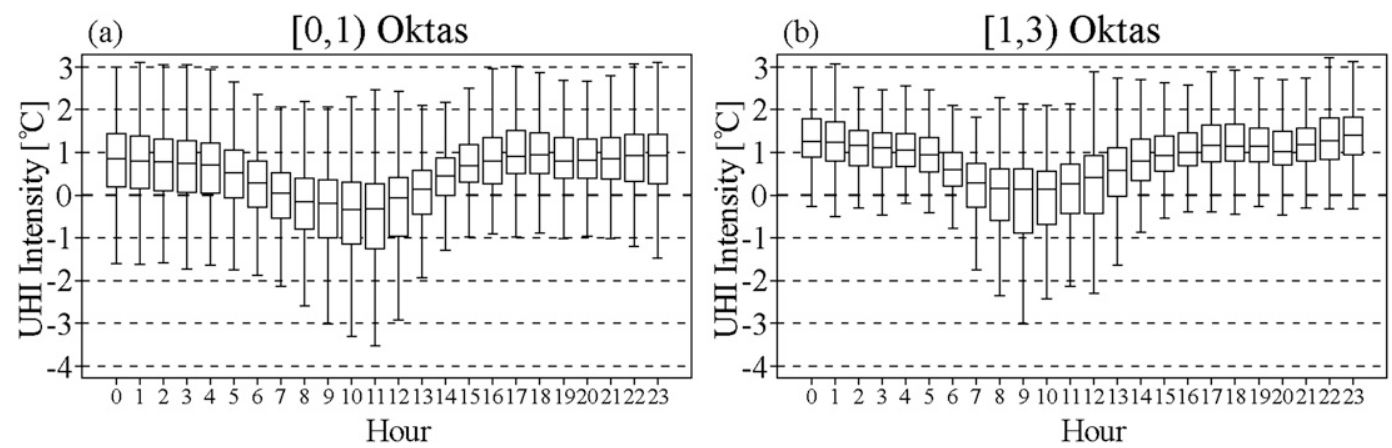

(c)

$[3,5)$ Oktas

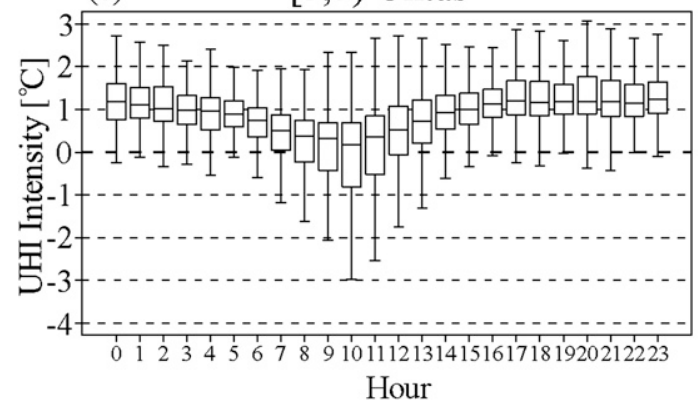

(d)

$[5,7)$ Oktas

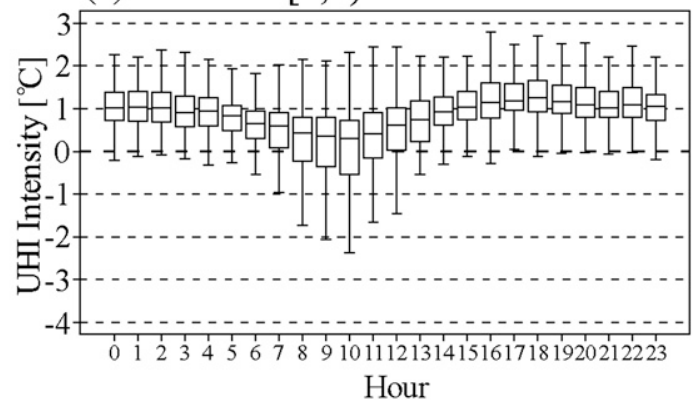

(e)

$[7,8]$ Oktas

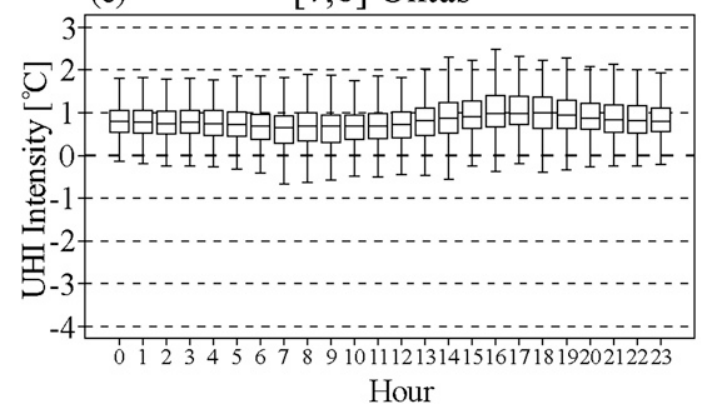

FIG. 9. As in Fig. 8, but for between Molino Vittoria and Laste.

wind speed affects temperature differences from the urban site. For this reason, generally valid conclusions for the stations on the sidewalls cannot yet be drawn.

To assess the influence of wind speed on the maximum diurnal UHI intensity, an analysis similar to that carried out for cloud cover was performed. In this case only the situations with cloud cover less than 2 oktas were analyzed. Results for Gardolo, on the valley floor, are shown in Fig. 12. The maximum UHI intensity displays only a weak dependence on wind speed. In particular, it is constant for wind speeds less than $2 \mathrm{~m} \mathrm{~s}^{-1}$, while beyond this value it decreases slightly as wind speed increases. This result is remarkably different from the relation proposed by Oke (1973), who found a strong dependence of UHI intensity on wind speed $u$ with a variation of $u^{-0.56}$. A similar dependence on wind speed was also found by Runnals and Oke (2000), while Morris et al. (2001) reported a slightly lower dependence. Furthermore, it is interesting to note from Fig. 12 that, even with

strong winds, high UHI intensities are possible (under cloudless conditions).

\section{g. Combination of cloud-cover and wind effects: The weather factor}

The weather factor $\Phi_{w}$ (Runnals and Oke 2000) was used to evaluate the combined effects of cloud cover and wind speed on the maximum diurnal UHI intensity. The original formulation of Runnals and Oke (2000) is as follows:

$$
\Phi_{w}=u^{-0.5}\left(1-k n^{2}\right)
$$

where $n$ is the cloud cover fraction (from 0 to 1 ), and $k$ is an empirical parameter taking into account the fact that cloudbase temperature decreases with height. Since measurements of cloud-base height were not available for this study, $k$ was taken to be constant and equal to 0.7 , which is the average of the values proposed by Oke (1987) for 


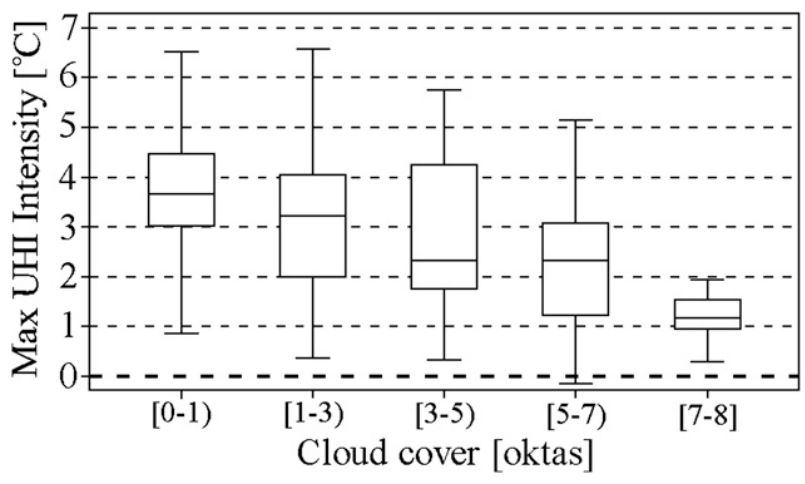

FIG. 10. As in Fig. 8, but for maximum diurnal temperature differences.

different cloud types. The weather factor can range from 0 to 1 , setting the cutoff for low speeds at $1 \mathrm{~m} \mathrm{~s}^{-1}$, with higher values indicating lower wind velocity and cloud cover.

In Fig. 13 the resulting box plot for Gardolo, on the valley floor, is shown. The maximum diurnal intensity of the UHI increases roughly linearly with the weather factor, with a slope of $2.53^{\circ} \mathrm{C} \mathrm{m}^{0.5} \mathrm{~s}^{-0.5}$ and an intercept of $1.32^{\circ} \mathrm{C}$. However, as can also be seen by the box plot, the data are quite scattered and the value of $R^{2}$ is only 0.20 . Notice that, for any value of the weather factor, the maximum diurnal UHI intensity may be negligible at some days, as highlighted by the low whiskers, whereas the high whiskers indicate strong UHI intensities occurring even with a weather factor as low as 0.4 .

\section{Conclusions and outlook on future developments}

A first insight into the UHI of Trento, in the Italian Alps, has been provided by analyzing the differences between air temperature time series registered at an urban station and at five surrounding extraurban weather stations over the period October 2002-December 2008.

Temperature contrasts strongly depend on the position of the extraurban weather stations. These are affected by different landscape and urbanization effects, reflecting the situation of a city located in an area of complex topography. In particular, three of the extraurban weather stations are located, as is the urban site, on the valley floor, while the other two are on the eastern slopes of the valley, one in the countryside and one in a suburban area. For these reasons the average temperature differences from the urban site vary considerably (between $0.6^{\circ}$ and $1.5^{\circ} \mathrm{C}$ ), if different extraurban weather stations are taken into account. These results emphasize the importance of carefully considering the position and local surroundings of the weather stations adopted to evaluate UHI intensity, in order to distinguish urbanization effects from site-dependent, local meteorological features, and to correctly interpret the results (Stewart 2010).

On the other hand, some general conclusions can be drawn from the diurnal cycles of the UHI intensity, which display similar properties at all the extraurban weather stations. The UHI is stronger during nighttime, when urban-rural temperature differences are quite constant throughout the night. During the same hours, the maximum diurnal UHI intensities are generally reached, with average values ranging between $2^{\circ}$ and $4^{\circ} \mathrm{C}$ at the extraurban stations on the valley floor. During the middle of the day the temperature at the urban site is usually lower than at the extraurban locations, with the development of an urban cool island. As a consequence, the diurnal temperature range at the urban site is considerably lower than that at the extraurban weather stations, where both warming and cooling rates are stronger. This consideration also holds inside the canopy layer, where, during two field measurements in an urban canyon, heating and cooling rates were found to be similar to those occurring at the urban station on the tower.

The analysis of the maximum diurnal intensity of the UHI highlighted that, under "ideal" conditions, values higher than $6^{\circ} \mathrm{C}$ can be reached. This result seems in agreement with maximum UHI intensities found in other European cities similar in size to Trento, and in particular Stolberg (Kuttler et al. 1996), one of the few studied cities located in a valley.

As to the urban cool island effect, its typical maximum intensity was found to be of order $1.5^{\circ} \mathrm{C}$, on the valley floor. Results from the field campaigns suggest that the strength of the urban cool island in the canopy layer would be lower, especially during the summer. However, in wintertime a quite strong urban cool island is also likely to occur in the canopy layer, especially in the more compact areas, due to overshadowing.

Considering the extraurban weather stations located on the valley floor, the seasonal variations of UHI intensity are negligible over daytime. On the other hand, during the nighttime the UHI intensity is slightly stronger during dry months, when weather conditions favor stronger radiative cooling. As to the extraurban stations located on the slopes, the seasonal variations of UHI intensity seem to be mainly affected by the seasonal change in the mean lapse rate rather than by urbanization effects. In fact during both daytime and nighttime, UHI intensity is lower during winter months, when the mean lapse rate is lowered by frequent thermal inversions.

The analyses of the impacts of cloud cover and wind speed on the diurnal UHI cycle highlighted that in the case of Trento the former is the meteorological factor that most influences UHI intensity: being connected with 
(a)

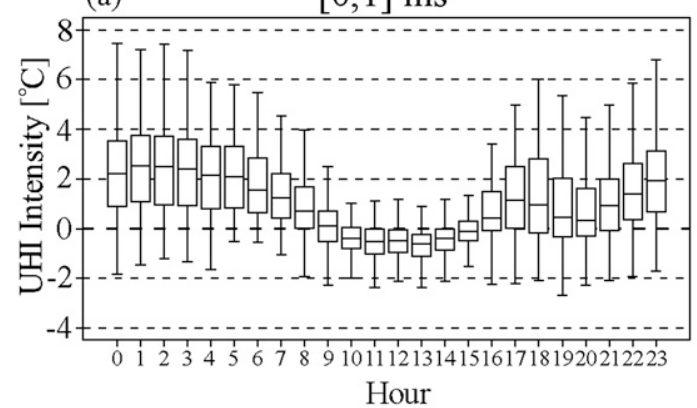

(c)

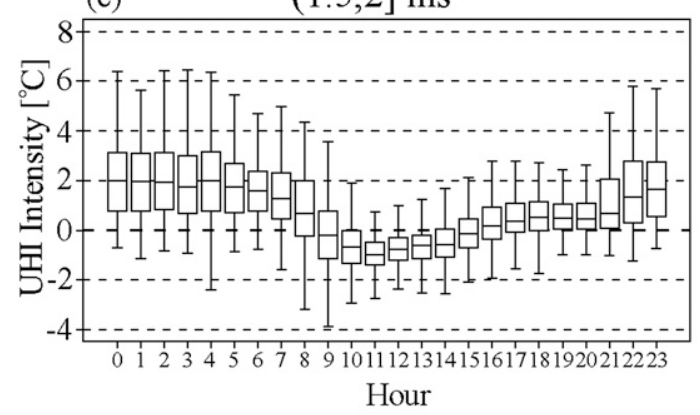

(e)

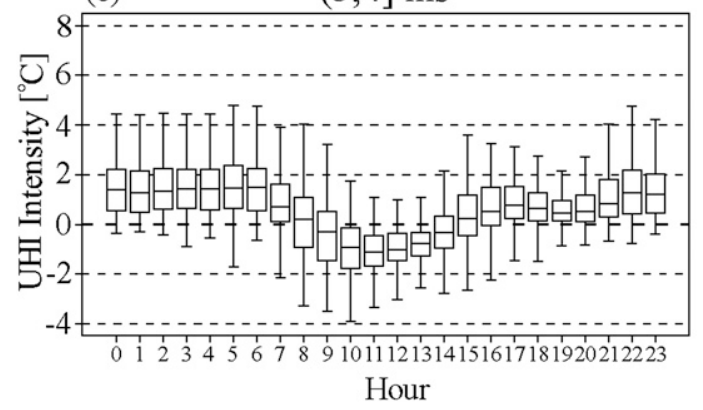

(b)

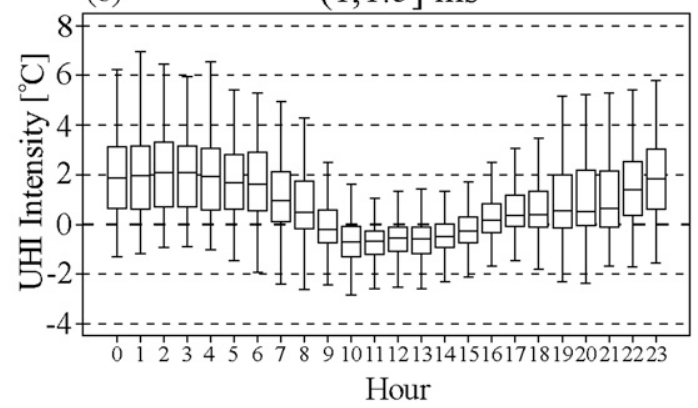

(d)
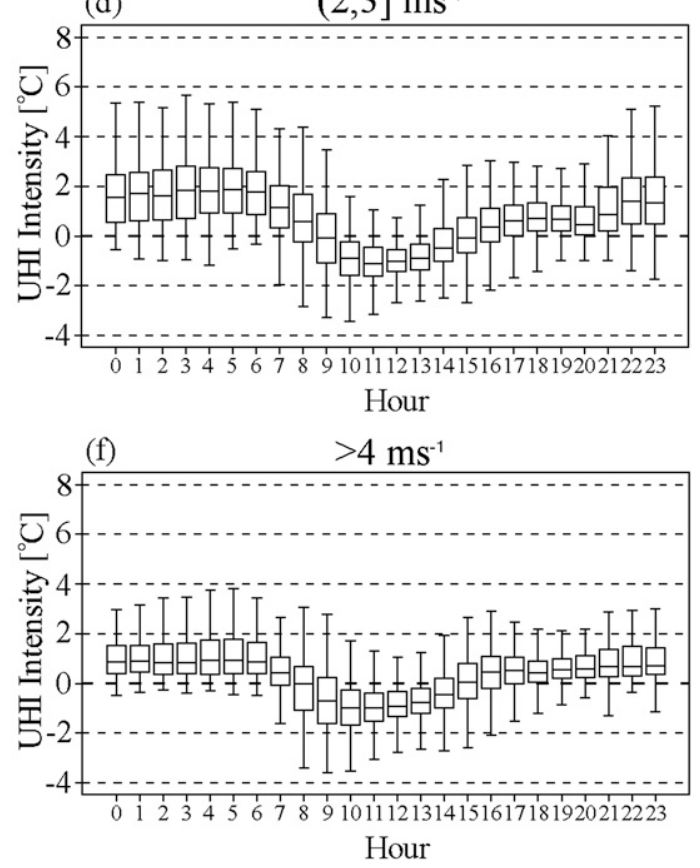

FIG. 11. As in Fig. 8, but classified by wind speed classes measured at Molino Vittoria.

solar radiation during the daytime and with radiative cooling at night, it affects directly both heating and cooling rates and, hence, their differences between urban and rural areas. For this reason temperature contrasts due to urbanization effects are appreciable under clear-sky conditions, becoming negligible for a completely cloudy sky.

As to the wind speed influence, it was found that this meteorological factor affects the diurnal cycle of the UHI at the extraurban weather stations on the valley floor only at night, when urban-rural temperature differences decrease slightly as the wind speed increases. No significant results were found for the two extraurban weather stations on the sidewalls, probably because the wind speed at Molino Vittoria is not fully representative of the situation on the slopes of the valley.

The analyses presented in this paper have some inherent limits, as they are based on single surface data only, which cannot give a complete spatial representation of the phenomena. For this reason some aspects, such as the assessment of the three-dimensional temperature and wind fields in the surroundings of the city, and in particular the interactions between local wind systems and the built-up area, will require further investigations. Among the few examples of local wind effects on UHI intensity, it was noted (but not shown here) that on the valley floor in spring and summer, as opposed to the winter period, UHI intensity is very low or negligible in the late evening. This behavior may be caused both by the later sunset, and (mostly) by the strong up-valley wind, which inhibits radiative cooling in the rural areas and tends to homogenize the surface temperature in the whole region. Moreover, the interaction between cold-air drainage flow and the built-up area is not completely clear. The drainage flow contributes to an earlier onset of strong UHI intensities on the sidewalls, but the situation on the valley floor needs further investigation. Wind measurements at the 


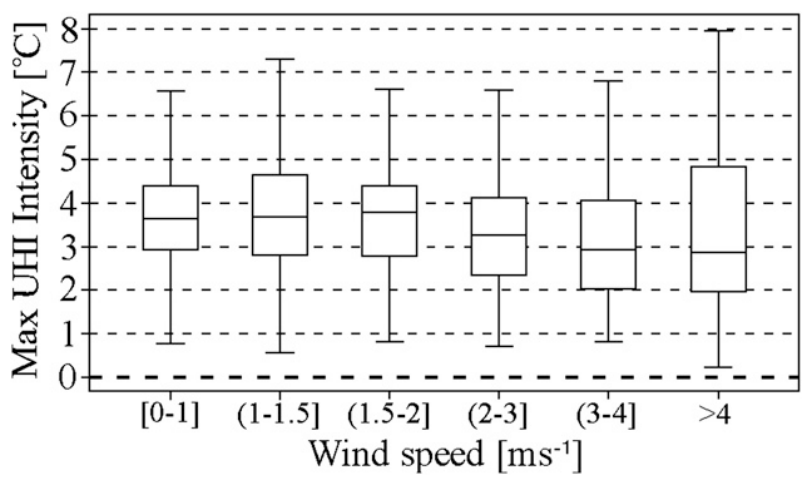

FIG. 12. As in Fig. 8, but for the maximum diurnal temperature differences classified by wind speed classes measured at Molino Vittoria.

urban reference station, located at about twice the height of the surrounding buildings, suggest that downvalley wind is generally rather strong and persistent at night over the urban area. However, in the absence of measurements inside the urban canopy layer, it is not clear if the flow penetrates below the roof level. One possibility is that the down-valley wind bypasses the urban area, flowing along preferential lanes, such as the lower-level corridor offered by the Adige riverbed. To investigate in depth all of these aspects, simulations with a mesoscale model, coupled with an urban parameterization scheme, are under way. Moreover, as has also been pointed out in the present work, temperature differences between the canopy layer and the air above roof level are being investigated by means of field measurements taken within a representative street canyon. A companion project, including use of a suitable numerical model for the determination of air temperature in the canopy layer, starting from meteorological measurements taken at a reference level over the urban area, will provide the opportunity for further comparisons.

This survey of the urban thermal fingerprint of Trento will prove useful in view of the reconstruction and analysis of the long temperature time series (1816-2010) of the city (Rea et al. 2003), as it will provide criteria to discriminate between temperature variations due to climatic change and those caused by the growth of the city in the last two centuries (cf. Andrighetti et al. 2009). In fact since 1816 temperature measurements were performed in several observatories, sited in different part of the city, and some of these locations were later progressively incorporated into the urban area. In addition, to evaluate the systematic temperature differences existing nowadays between the different observatories, a field measurement is in progress, with five identical temperature and humidity sensors placed in the exact locations where historical observations were performed. The results of this field campaign

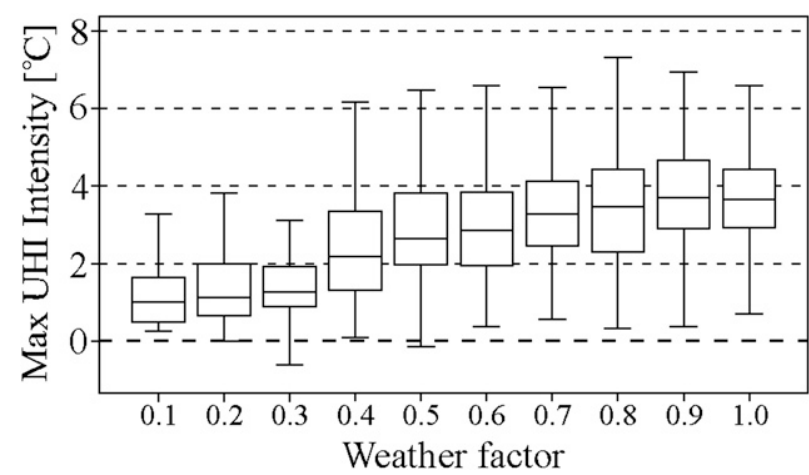

FIG. 13. As in Fig. 8, but for maximum diurnal temperature differences as a function of the weather factor.

will provide further elements for the assessment of differences in the microclimatic effects inside the urban area.

Acknowledgments. The Agrometeorological Unit of the Istituto Agrario di San Michele all'Adige, operated by the Edmund Mach Foundation, is kindly acknowledged for the temperature and wind direction data from the Gardolo, Trento South, and Cognola weather stations. The Meteorological Office of the Autonomous Province of Trento ("Meteotrentino") is kindly acknowledged for temperature data at Roncafort weather station and for temperature and wind direction data at the Laste weather station. The Italian Center for Meteorology and Climatology of the Italian Air Force and www.wunderground.com are kindly acknowledged for data concerning cloud cover at the Mount Paganella weather station. The Municipality of Trento is kindly acknowledged for providing datasets from lidar scans of the urban area. Special thanks are given to Dr. Richard Rotunno for reading and making corrections to the manuscript and to Dr. Ekkehard Dreiseitl for providing useful information about classic contributions about valley winds in Trento basin.

\section{REFERENCES}

Andrighetti, M., D. Zardi, and M. de Franceschi, 2009: History and analysis of the temperature series of Verona (1769-2006). Meteor. Atmos. Phys., 103, 267-277.

Bacci, P., and M. Maugeri, 1992: The urban heat island of Milan. Nuovo Cimento, 15C, 417-424.

Cenedese, A., and P. Monti, 2003: Interaction between an inland urban heat island and a sea-breeze flow: A laboratory study. J. Appl. Meteor., 42, 1569-1583.

Colacino, M., and A. Lavagnini, 1982: Evidence of the urban heat island in Rome by climatological analyses. Arch. Meteor. Geophys. Bioklimatol., 31, 87-97.

de Franceschi, M., and D. Zardi, 2007: L'Osservatorio meteorologico dell'Università degli Studi di Trento al "Molino Vittoria" (The Meteorological Observatory of the University 
of Trento at the "Molino Vittoria"). Dipartimento di Ingegneria Civile e Ambientale, Università degli Studi di Trento, $36 \mathrm{pp}$. [Available online at http://www.ing.unitn.it/dica/tools/ download/Quaderni/Libro_Molino_Final.pdf.]

- and _ 2009: Study of wintertime high pollution episodes during the Brenner-South ALPNAP measurement campaign. Meteor. Atmos. Phys., 103, 237-250.

- G. Rampanelli, and D. Zardi, 2002: Further investigations of the "Ora del Garda" valley wind. Preprints, 10th Conf. on Mountain Meteorology and MAP Meeting 2002, Park City, UT, Amer. Meteor. Soc., 3.2. [Available online at http:// ams.confex.com/ams/pdfpapers/39949.pdf.]

-,- , D. Sguerso, D. Zardi, and P. Zatelli, 2003: Development of a measurement platform on a light airplane and analysis of airborne measurements in the atmospheric boundary layer. Ann. Geophys., 46, 269-283.

— , D. Zardi, M. Tagliazucca, and F. Tampieri, 2009: Analysis of second order moments in the surface layer turbulence in an Alpine valley. Quart. J. Roy. Meteor. Soc., 135, 17501765.

De Wekker, S. F. J., and C. D. Whiteman, 2006: On the time scale of nocturnal boundary layer cooling in valleys and basins and over plains. J. Appl. Meteor. Climatol., 45, 813-820.

Gedzelman, S. D., S. Austin, R. Cermak, N. Stefano, S. Partridge, S. Quesenberry, and D. A. Robinson, 2003: Mesoscale aspects of the urban heat island around New York City. Theor. Appl. Climatol., 75, 29-42.

Goldreich, Y., 1984: Urban topoclimatology. Prog. Phys. Geogr., 8, 336-364.

- 2009: Updating the urban topoclimatology-A review. Extended Abstracts, The Seventh Int. Conf. on Urban Climate, Yokohama, Japan, Int. Association for Urban Climate, P3-47.

Grigiante, M., F. Mottes, D. Zardi, and M. de Franceschi, 2011: Experimental solar radiation measurements and their effectiveness in setting up a real sky irradiance model. Renew. Energy, 36, 1-8.

Jauregui, E., 1987: Urban heat island development in medium and large urban areas in Mexico. Erdkunde, 41, 48-51.

Junk, J., A. Helbig, and J. Lüers, 2003: Urban climate and air quality in Trier, Germany. Int. J. Biometeor., 47, 230-238.

Kassomenos, P. A., and B. D. Katsoulis, 2006: Mesoscale and macroscale aspects of the morning urban heat island around Athens, Greece. Meteor. Atmos. Phys., 94, 209-218.

Kim, Y.-H., and J.-J. Baik, 2002: Maximum urban heat island intensity in Seoul. J. Appl. Meteor., 41, 651-659.

Kljun, N., P. Calanca, M. W. Rotach, and H. P. Schmid, 2004: A simple parameterisation for flux footprint predictions. Bound.-Layer Meteor., 112, 503-523.

Kuttler, W., A.-B. Barlag, and F. Roßmann, 1996: Study of the thermal structure of a town in a narrow valley. Atmos. Environ., 30, 365-378.

_ - D. Dutemeyer, and A.-B. Barlag, 1998: Influence of regional and local winds on urban ventilation in Cologne, Germany. Meteor. Z., 7, 77-87.

Landsberg, H. E., 1981: The Urban Climate. Academic Press, $275 \mathrm{pp}$.

Lazar, R., and A. Podesser, 1999: An urban climate analysis of Graz and its significance for urban planning in the tributary valleys east of Graz (Austria). Atmos. Environ., 33, 4195-4209.

Lee, S.-H., and J.-J. Baik, 2010: Statistical and dynamical characteristics of the urban heat island intensity in Seoul. Theor. Appl. Climatol., 100, 227-237.
Lowry, W. P., 1977: Empirical estimation of urban effects on climate: A problem analysis. J. Appl. Meteor., 16, 129-135.

Morris, C. J. G., and I. Simmonds, 2000: Associations between varying magnitudes of the urban heat island and the synoptic climatology in Melbourne, Australia. Int. J. Climatol., 20, 1931-1954.

,-- , and N. Plummer, 2001: Quantification of the influences of wind and cloud on the nocturnal urban heat island of a large city. J. Appl. Meteor., 40, 169-182.

Municipality of Trento, cited 2009: Trento statistica, la popolazione al 31 dicembre 2008 (Statistical Trento, population at 31 December 2008). [Available online at http://www.comune.tn.it/ trento/trento65.nsf/51683109be521632c12572d6003045e5/ fe524280c696922ac12575700045b15c/\$FILE/trento_statistica_ 2008.pdf.]

Nkemdirim, L. C., 1980: Cold air drainage and temperature fields in an urban environment: A case study of topographical influence on climate. Atmos. Environ., 14, 375-381.

Oke, T. R., 1973: City size and the urban heat island. Atmos. Environ., 7, 769-779.

1976: The distinction between canopy and boundary-layer urban heat islands. Atmosphere, 14, 268-277.

_ 1987: Boundary Layer Climates. 2nd ed. Routledge, 435 pp.

_ and C. East, 1971: The urban boundary layer in Montreal. Bound.-Layer Meteor., 1, 411-437.

Piringer, M., and K. Baumann, 1999: Modifications of a valley wind system by an urban area-Experimental results. Meteor. Atmos. Phys., 71, 117-125.

Pollak, L. W., 1924: Berg- und Talwinde im Becken von Trient (Mountain and valley winds in Trento basin). Meteor. Z., 41, $18-21$.

Rampanelli, G., and D. Zardi, 2004: A method to determine the capping inversion of the convective boundary layer. J. Appl. Meteor., 43, 925-933.

, - — , and R. Rotunno, 2004: Mechanisms of up-valley winds. J. Atmos. Sci., 61, 3097-3111.

Rea, R., G. Rampanelli, and D. Zardi, 2003: The temperature series of Trento: 1816-2002. Proc. 27th Int. Conf. on Alpine Meteorology and MAP Meeting, Vol. A, Brig, Switzerland, MeteoSwiss and Institute for Atmospheric and Climate Science ETH, 483-486.

Rotach, M., and D. Zardi, 2007: On the boundary layer structure over highly complex terrain: Key findings from MAP. Quart. J. Roy. Meteor. Soc., 133, 937-948.

Runnals, K. E., and T. R. Oke, 2000: Dynamics and controls of the near-surface heat island of Vancouver, British Columbia. Phys. Geogr., 21, 283-304.

Sadler, F., and A. Bellin, 2004: Analisi di serie storiche di precipitazione (Analysis of historical precipitation time series). Analisi Climatologica delle Serie Storiche delle Precipitazioni e Temperature in Trentino (Climatologic analysis of historical precipitation and temperature time series in Trentino), A. Bellin and D. Zardi, Eds., Editoriale Bios, 11-133.

Schaller, E., 1936: Aerologische Untersuchung des periodischen Talwindsystems von Trient (Aerologic investigation of the periodic valley-wind system of Trento). M.S. Thesis, Institute for Cosmic Physics, Philosophical Faculty, Innsbruck University, $62 \mathrm{pp}$.

Schmidlin, T. W., 1989: The urban heat island at Toledo, Ohio. Ohio J. Sci., 89, 38-41.

Serafin, S., and D. Zardi, 2010a: Structure of the atmospheric boundary layer in the vicinity of a developing upslope flow system: A numerical model study. J. Atmos. Sci., 67, 1171-1185. 
— and 2010b: Daytime heat transfer processes related to slope flows and turbulent convection in an idealized mountain valley. J. Atmos. Sci., 67, 3739-3756.

Steinecke, K., 1999: Urban climatological studies in the Reykjavík subarctic environment, Iceland. Atmos. Environ., 33, 4157-4162.

Stewart, I. D., 2010: A systematic review and scientific critique of methodology in modern urban heat island literature. Int. J. Climatol., 31, 200-217, doi:10.1002/joc.2141.

Thompson, W. T., T. Holt, and J. Pullen, 2007: Investigation of a sea breeze front in an urban environment. Quart. J. Roy. Meteor. Soc., 133, 579-594.

Unwin, D. J., 1980: The synoptic climatology of Birmingham's heat island. Weather, 35, 43-50.
Wagner, A., 1938: Theorie und Beobachtung der periodischen Gebirgswinde (Theory and observation of periodic mountain winds). Gerlands Beitr. Geophys., 52, 408-449.

Wanner, H., and J.-A. Hertig, 1984: Studies of urban climates and air pollution in Switzerland. J. Climate Appl. Meteor., 23, 1614-1625.

Whiteman, C. D., 1990: Observation of thermally developed wind systems in mountainous terrain. Atmospheric Processes over Complex Terrain, Meteor. Monogr., No. 45. Amer. Meteor. Soc., 5-42.

Zauli Sajani, S., S. Tibaldi, F. Scotto, and P. Lauriola, 2008: Bioclimatic characterisation of an urban area: A case study in Bologna (Italy). Int. J. Biometeor., 52, 779-785. 